\title{
Development of Functional Materials Based on Carbon/Manganite/Ferrite Composites for Microwave Absorber Materials Applications
}

\author{
Maya Puspitasari Izaak*, Yohanes Edi Gunanto, and Henni Sitompul \\ Department of Physics Education, Universitas Pelita Harapan Karawaci, Tangerang 15811, Indonesia \\ Wisnu Ari Adi \\ Center for Science and Technology of Advanced Materials, BATAN, Tangerang Selatan 15314, Indonesia
}

\begin{abstract}
The synthesis of carbon/manganite/ferrite composite materials for microwave absorber applications has been successfully carried out with variations in the composition of 15:55:30 and 15:45:40 (wt\%). This composition was successfully confirmed based on the analysis of the X-ray diffraction pattern using the GSAS program. The refinement results show that each phase of each composite has a good structure. Based on surface morphological observations, it is known that the composite samples have varying particle sizes of around 150-500 nm which are evenly distributed over the entire surface of the sample. The result of the microwave absorption analysis implies that the difference in composition results in a slight increase of the reflection loss and the presence of a new absorption peak at a frequency of $4.36 \mathrm{GHz}$. Our result underlines that the characteristic of microwave absorption in composites is insignificantly influenced by the composition of the material as the absorption properties are mainly affected by the respective phases that form it, not by the entire phase of the composite.
\end{abstract}

\author{
Keywords: composite, carbon-manganite-ferrite, composition, microwave absorber \\ *Corresponding author: maya.izaak@uph.edu \\ Article history: Received 25 Maret 2021, Accepted 19 Juni 2021, Published June 2021. \\ http://dx.doi.org/10.12962/j24604682.v17i2.8978 \\ 2460-4682 (CDepartemen Fisika, FSAD-ITS
}

\section{INTRODUCTION}

The development of science and technology has led to the emergence of sophisticated weapons being produced and used in various developed countries. Various applications of advanced technology are used as solutions to overcome emerging new threats to the strategic environment in each country. In the military, microwave (radar wave) is used as a tool for visualizing targets. Radar (Radio detection and ranging) is able to detect targets for information in the form of distance, azimuth, and speed. Microwaves are useful for detecting distances and even making maps of information an object with the X-Band frequency range between 8-12 GHz which are known as military radar operations [1].

The strength of the radar signal with today's technological developments can be identified by describing the distance, location, shape and size of the target identified as the Radar Cross Section (RCS). Therefore, to reduce detection from radar, a reduction of the signal is needed to be considered. The principle of the radar absorbing material (RAM) is to reduce the emitted energy in the collision material which reduces the echo energy in the radar signal $[2,3]$. There are several techniques used as RCS reductors, namely shaping, jamming, and distributed loading techniques. The distributed loading technique is most useful for covering carrier materials as a transfer of electromagnetic energy and energy absorption $[4,5]$. Radar waves are essential in a surveillance technology, imaging and tracking with a certain spectrum to convey information. A method to overcome problems limiting RAM performance is to design composite-based materials. Therefore, the current study aims to synthesize and characterize magnetic composite materials based on carbon/manganite/ferrite with certain combinations to be able to absorb radar waves.

As electromagnetic waves consist of vector components of electric and magnetic fields, a material is theoretically able to absorb electromagnetic waves, especially for the material that has good permittivity (electrical properties) and permeability (magnetic properties) [6]. In this study, the prepared composite material is consisted of constituent compounds that have good permittivity (manganite) [7] and permeability (ferrite) [8]. By combining the two materials with the carbon matrix, it is expected to become a good absorber material for electromagnetic waves especially microwaves [9].

Manganite/Ferrite composite material is a functional material that is very promising in its application in the fields of science and technology [10]. The previous study have shown that manganite is one of the candidates for microwave absorber material which has a good permittivity [11], and ferrite is known to has a good permeability [12]. Meanwhile, carbon is a material that has long been known to be used as an absorbent material for microwaves, although it has a relatively small absorption capacity [13]. However, because car- 


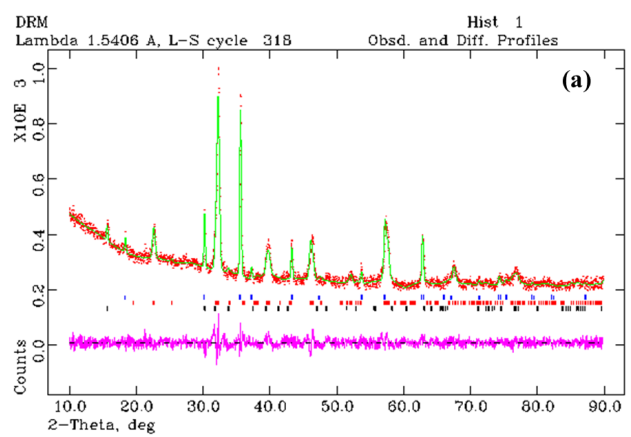

(a)
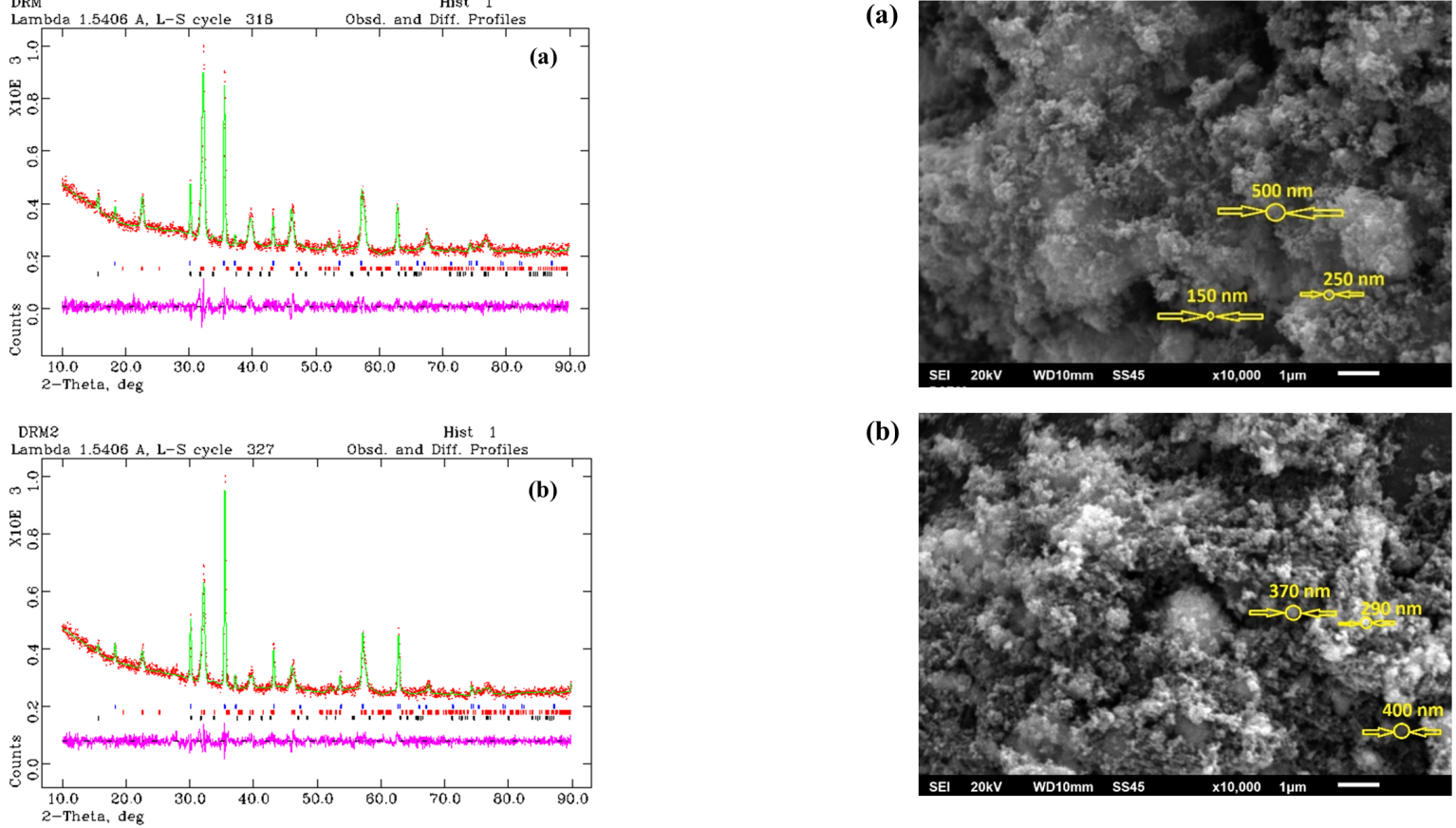

FIG. 1: Refinement results of the XRD pattern obtained with GSAS software: (a) composite 15:55:30 and (b) composite 15:45:40

bon is a light material and presents in a fine powder [9], it is estimated to be a composite medium between manganite and ferrite. In this study, the composition of the carbon material is determined to be the same, while the composition of manganite and ferrite is varied with the purpose that the impact of changes in absorption characterization would be clarified. Here, carbon/manganite/ferrite composites has been prepared with a ratio of 15:55:30 and 15:45:40 to determine the effect of constituent composition to the microwaves absorption.

\section{MATERIALS AND METHODS}

This research is a preliminary study of making composites, so that only raw materials that have not been modified such as carbon, manganite $\left(\mathrm{LaMnO}_{3}\right)$ and ferrite $\left(\mathrm{Fe}_{3} \mathrm{O}_{4}\right)$ are used. Before making composites, $\mathrm{LaMnO}_{3}$ must first be prepared. $\mathrm{LaMnO}_{3}$ is made from raw materials $\mathrm{La}_{2} \mathrm{O}_{3}$ and $\mathrm{MnO}_{2}$ which are processed by the solid reaction method using high energy milling (HEM) for 5 hours. It was the sintered at $1000^{\circ} \mathrm{C}$ for 5 hours. Carbon/manganite/ferrite composite samples were prepared with the composition of $\mathrm{C}: \mathrm{LaMnO}_{3}: \mathrm{Fe}_{3} \mathrm{O}_{4}$ of $5: 55: 30$ and 15:45:40. This composite is mixed using HEM for 5 hours before characterized.

The characteristics of the composites such as phases, particle size, and microwave absorbing performance were analyzed using various techniques such as XRD (X-ray diffractometer), SEM (scanning electron microscope), and VNA (Vector Network Analyzer), respectively. The XRD Philip PW1710 is used with a wavelength $\lambda=1.5406 \AA$. The quan-
FIG. 2: SEM image result of the composite with composition of (a) 15:55:30 and (b) 15:45:40

titative analysis of XRD data was performed using general structure analysis system (GSAS) software [14]. Surface morphology was examined using SEM. The ability of the material to absorb microwaves was evaluated using VNA MS46322A with a frequency range from 4 to $8 \mathrm{GHz}$ (C-band frequency).

\section{RESULTS AND DISCUSSION}

The working principle of this XRD device is based on Bragg's law. Fig. 1 shows the refinement results of XRD patterns with the GSAS program. GSAS, one of the XRD data analysis programs, is based on the Rietveld method. Based on the analysis using the GSAS program, the quantitative number of each phase in the composite and the structural parameters are obtained. The success of this analysis is determined by statistical factors in the form of the value of wRp, which must less than $10 \%$, and $\chi^{2}$,which should less than 1.3 . These values are relatively small in accordance with the Rietveld method code [14].

The small value of $w R p$ and $\chi^{2}$ indicates that the fitting between the calculation and observed results is relatively good. The carbon orthorombic structure was also obtained by Oganov, et al. [15] and Wei, et al. [16]. Schmitt, et al. [17] also found that $\mathrm{LaMnO}_{3}$ has an orthorombic structure, while the cubic structure for $\mathrm{Fe}_{3} \mathrm{O}_{4}$ was also obtained by Gunanto, et al. [18].

The results of the refinement of the XRD pattern of the two composites show the presence of the manganite phase as a main peak at $2 \theta$ of $32.37^{\circ}$. The intensity seems to decrease, 
TABLE I: Structural parameter determined from the refinement result of the composite 15:55:30

\begin{tabular}{|c|c|c|c|c|c|c|}
\hline \multicolumn{3}{|c|}{ wRp: 5.72} & \multicolumn{4}{|c|}{$\chi^{2}$ (Chi square): 1.062} \\
\hline \multirow{2}{*}{ Phase } & \multirow{2}{*}{ System } & \multirow{2}{*}{ Space Group } & \multicolumn{2}{|c|}{ Lattice Parameters } & \multirow{2}{*}{$\mathrm{V}\left(\AA^{3}\right)$} & \multirow{2}{*}{ rho $\left(\mathrm{g} / \mathrm{cm}^{3}\right)$} \\
\hline & & & $\mathrm{b}$ & $\mathrm{c}$ & & \\
\hline $\mathrm{C}$ & Ort & & $4.597(1) 5.3$ & 5.785 & & 2.33 \\
\hline $\mathrm{LaMnO}_{3}$ & Orthorombic & $\mathrm{Pbnm}$ & $5.538(1) 5.603(1)$ & $7.823(3)$ & $.7(1)$ & 6.615 \\
\hline $\mathrm{Fe}_{3} \mathrm{O}_{4}$ & Cubic & $F d-3 m$ & 8.369(1) 8.369(1) & $8.369(1)$ & $586.3(2)$ & 5.247 \\
\hline
\end{tabular}

TABLE II: Structural parameter determined from the refinement result of the composite 15:45:40

\begin{tabular}{|c|c|c|c|c|c|c|}
\hline \multicolumn{3}{|c|}{ wRp: 5.58} & \multirow{2}{*}{\multicolumn{4}{|c|}{$\begin{array}{l}\chi^{2} \text { (Chi square): } 1.059 \\
\text { Lattice Parameters }\end{array}$}} \\
\hline \multirow{2}{*}{ Phase } & \multirow{2}{*}{ System } & \multirow{2}{*}{ Space Group } & & & & \\
\hline & & & $\begin{array}{ll}\mathrm{a} & \mathrm{b}\end{array}$ & $\mathrm{c}$ & A) & $\operatorname{lno}(\mathrm{g} / \mathrm{cm})$ \\
\hline $\mathrm{C}$ & Ortho & & $4.620(1) 5.335(1)$ & $5.708(2)$ & $140.7(9)$ & 2.303 \\
\hline $\mathrm{LaMnO}_{3}$ & Orthorombic & $\mathrm{Pb} \mathrm{nm}$ & $5.539(1) 5.607(1)$ & $7.825(3)$ & $243.0(1)$ & 6.608 \\
\hline $\mathrm{Fe}_{3} \mathrm{O}_{4}$ & Cubic & $\mathrm{F} \mathrm{d}-3 \mathrm{~m}$ & $8.370(1) 8.370(1)$ & $8.370(1)$ & $586.4(2)$ & 5.245 \\
\hline
\end{tabular}

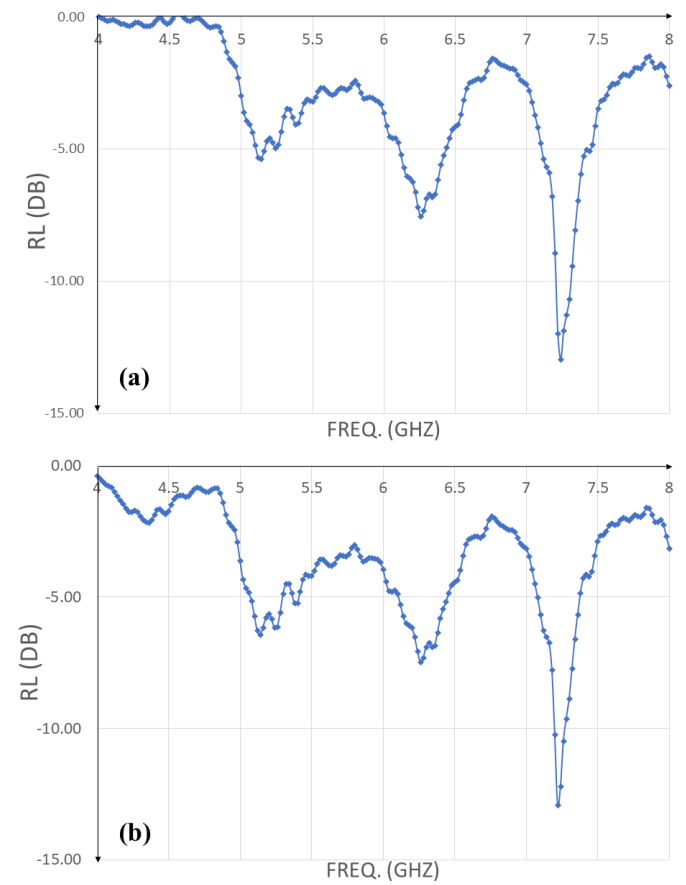

FIG. 3: Reflection Loss (RL) of the composites with composition of (a) 15:55:30 and (b) 15:45:40

while the peak of the ferrite phase at $2 \theta$ of $35.44^{\circ}$ tends to increase. This means that the ferrite phase content in the composition increases in accordance with the expected composition.

The detail results of XRD characterization and structural parameter of refinement result are summarized in Table 1 and Table 2, respectively. Each composites consists of a carbon (C), manganite $\left(\mathrm{LaMnO}_{3}\right)$ and ferrite $\left(\mathrm{Fe}_{3} \mathrm{O}_{4}\right)$ phases with an appropriate structure, indicating that the mixing process does not cause damage to the structure of each phase. This can be seen from the volume of the unit cell and the atomic density of each phase in the composite which has relatively the same value. In addition to that, the phase composition in each composites is close to the expected composition.

The results of the XRD refinement are also supported by observations of particle surface morphology for the two composites using SEM with a magnification of 10000 times as shown in Fig. 2. The composites consists of particles that vary in size from $150-500 \mathrm{~nm}$, which can be easily seen by comparing the particle diameter with the existing line scales in Fig. 2. The results shows that the composites are very heterogeneous with an even distribution over the entire surface of the sample. Moreover, it was found that agglomeration in the sample was caused by the surface interaction of the $\mathrm{Fe}_{3} \mathrm{O}_{4}$ magnetic particles wrapped in carbon particles.

The ability of a material to absorb microwaves is represented in reflection loss (RL). The amount of reflection loss (RL) is calculated by Eq. (1) [19]:

$$
R L(d B)=20 \log \left|\frac{Z_{i n}-1}{Z_{i n}+1}\right|
$$

where

$$
Z_{i n}=\left(\frac{\mu_{r}}{\epsilon_{r}}\right)^{\frac{1}{2}} \tanh \left[j\left(\frac{2 n f d}{c}\right)\left(\mu_{r} \epsilon_{r}\right)^{\frac{1}{2}}\right]
$$

Here, $Z_{\text {in }}$ is the input impedance of the absorber, $\mu_{r}$ and $\epsilon_{r}$ are the permeability and relative permeability of the medium, respectively. $f$ is the microwave frequency, $d$ is the thickness of the absorber, and $c$ is the speed of light.

Fig. 3 shows the results of RL measurements using a vector network analyzer (VNA) with a C-band adapter $(4-8 \mathrm{GHz})$. The obtained maximum RL values for composites with the composition of 15: 55: 30 and 15:45:40 are $-12.93 \mathrm{~dB}(f=$ $7.22 \mathrm{GHz})$ and $-19.96 \mathrm{~dB}(f=7.24 \mathrm{GHz})$, respectively. The detailed results of this VNA characterization can be seen in Table 3.

Based on Fig. 3 and Table 3, it is shown that in the 15:55:30 composition the microwaves absorption occurs at three differ- 
TABLE III: Summary of the composite's ability to absorb microwaves

\begin{tabular}{lll}
\hline Composite & RL $(\mathrm{dB})$ & $f(\mathrm{GHz})$ \\
\hline $15: 55: 30$ & -5.38 & 5.14 \\
& -7.56 & 6.26 \\
& -12.93 & 7.22 \\
\hline $15: 45: 40$ & -2.17 & 4.36 \\
& -6.45 & 5.14 \\
& -7.57 & 6.26 \\
& -12.96 & 7.24 \\
\hline
\end{tabular}

ent frequencies, while in the composition 15:45:40 the absorption takes place at four different frequencies. There are also an increase in the RL. Even though it is not significant, but a slight increase in the microwave absorption at a frequency of $4.36 \mathrm{GHz}$ was observed. This means that changes in the composition of manganite and ferrite may not significantly affect the microwaves absorption, which probably due to the absence of a chemical interaction between one phase with another in the composites. As the result, the microwave absorp- tion mechanism caused by the resonance of the electric and magnetic dipole moments do not go together, and the absorption only occurs in each material in the composite.

\section{SUMMARY}

In this research, carbon/manganite/ferrite composites have been successfully prepared with the composition of 15:55:30 and 15:45:40. The obtained composites consist of rather heterogeneous particles, having the size in the range of 150-500 $\mathrm{nm}$. A slight increase in the microwave absorption is observed after the composition of the composite changes, especially at the frequency of $4.36 \mathrm{GHz}$.

\section{Acknowledgment}

This work was supported by Universitas Pelita Harapan Grants 2019 with the number: P-023/FIP/I/2020.
[1] Gustomo, et al., "Analisa penggunaan sinyal radar bentuk pulsa dan gelombang kontinyu untuk target bergerak dengan model clutter terdistribusi Rayleigh,” in Jurnal Teknik ITS, Surabaya, Indonesia, 2013, vol. 2, no. 2, p. A235-A240.

[2] A. P. Mouritz, Introduction to Aerospace Materials. Britania Raya: Elsevier Science, 2012.

[3] L. C. Forgueras and M. C. Rezende. Multilayer radar absorbing material processing by using polymeric nonwoven and conducting polymer, in Materials Research, Brazil, 2008, vol. 11, no. 3 , p. $245-249$.

[4] E. L. Nasution and Astuti. Sintesis nanokomposit PAni/ $/ \mathrm{Fe}_{3} \mathrm{O}_{4}$ sebagai penyerap magnetik pada gelombang mikro, in Jurnal Fisika Unand, Padang, Indonesia. 2012, vol. 1 no. 1, p. 37-44.

[5] A. Qurrota and I. K. Murwanti. Impregnasi dan karakterisasi struktur padatan $\mathrm{Co}_{3} \mathrm{O}_{4}$ pada pendukung $\mathrm{CaF}_{2}$, in Jurnal Sains dan Seni ITS, Surabaya, Indonesia, 2012, vol. 1, no. 1, p C1-C3.

[6] P. Sardjono and W.A. Adi, Thermal analysis and magnetic properties of lanthanum barium manganite perovskite, in Journal of Advanced Materials Research, Yogyakarta, Indonesia, 2014, vol. 896, p 381-384.

[7] Y.E. Gunanto, et al., Microwave Absorbing Properties of $\mathrm{Ba}_{0.6} \mathrm{Sr}_{0.4} \mathrm{Fe}_{12-z} \mathrm{Mn}_{z} \mathrm{O}_{19}(z=0 \quad 3)$ Materials in X-Band Frequencies, in Journal of Mathematical and Fundamental Sciences ITB, Bandung, Indonesia, 2016, vol. 48, no. 1, p. 55-65.

[8] A. Fisli, et al., Iron oxide/titania composites for radar absorbing material applications, in Cerâmica, Brazil, 2019, vol 65, p. 470476.

[9] Yusmaniar, et al., Carbon Extraction from Rice Husk and its Application as a Microwave Adsorbent, in Key Engineering Materials, Bandung, Indonesia, 2020, vol. 860, p. 178-184,

[10] Y. Shlapa, et al. Iron-Doped ( $\mathrm{La}, \mathrm{Sr}) \mathrm{MnO}_{3}$ Manganites as Promising Mediators of Self-Controlled Magnetic Nanohyper- thermia. in Nanoscale Research Letters , 2016, vol. 11, p. 24.

[11] G.Muscas, et al., Designing new ferrite/manganite nanocomposites, in Nanoscale, 2016, vol. 8, p. 2081-2089.

[12] L.B.Kong, et al., Recent progress in some composite materials and structures for specific electromagnetic applications, in International Materials Reviews, 2013, vol. 58, Issues 4, p. 203259.

[13] D. K. Setua, et al., Chapter 18 - Carbon nanofibers-reinforced polymer nanocomposites as efficient microwave absorber, in Fiber- Reinforced Nanocomposites: Fundamentals and Applications, Elsevier, 2020, Pages 395-430.

[14] B.H. Toby. EXPGUI A Graphical User Interface for GSAS, in Journal of Applied Crystallography. 2001, vol. 34 210-213.

[15] A. R. Oganov, et al., Structure, Bonding, and Mineralogy of Carbon at Extreme Conditions, in Reviews in Mineralogy Geochemistry, 2013, vol. 75, p. 47-77.

[16] Qun Wei, et al., A new superhard carbon allotrope: Orthorhombic C20, in Physics Letters A, 2018. vol. 382, Issue 25, p. 16851689.

[17] M.M. Schmitt, et al., Electron-lattice interplays in $\mathrm{LaMnO}_{3}$ from canonical Jahn-Teller distortion notations, in Phys. Rev. B, 2020, vol 101, no. 214304.

[18] Y..E. Gunanto, et al., High purity $\mathrm{Fe}_{3} \mathrm{O}_{4}$ from Local Iron Sand Extraction, in Journal of Physics: Conf. Series, 2018, vol. 1011, no. 012005 .

[19] J. Zhao, et al., Lanthanum and Neodymium Doped Barium Ferrite- $\mathrm{TiO}_{2} / \mathrm{MWCNTs} /$ poly(3-methyl thiophene) Composites with Nest Structures: Preparation, Characterization and Electromagnetic Microwave Absorption Properties, in Sci. Rep. 6 , 2016, no. 20496 